\title{
Stress and Burnout Among Surgical Oncologists: A Call for Personal Wellness and a Supportive Workplace Environment
}

\author{
Charles M. Balch, MD, FACS, ${ }^{1}$ and Edward Copeland, MD, FACS $^{2}$ \\ ${ }^{1}$ Johns Hopkins Medical Institutions, Surgery, Oncology, and Dermatology, 600 N. Wolfe St., Osler 624, Baltimore, \\ Maryland 21287, United States \\ ${ }^{2}$ University of Florida College of Medicine, Gainesville, Florida 32610-0266, USA
}

In this issue of the Annals of Surgical Oncology is a "must read" article about stress and burnout among surgical oncologists. ${ }^{1}$ This is the first time that our discipline has been surveyed about this important topic, and the results are important for each of us personally and for our profession. As practicing surgical oncologists for more than 30 years, we have both experienced stress and exhaustion during our careers. Yet, we have managed to be sustained through these times and look back on our careers with great satisfaction. It is tragic though, that some of our colleagues, after committing almost a decade of highly specialized training, suffer from burnout to a level that that they progressively become less productive, less efficient, or even leave their practice early. This is an issue that affects each one of us and should be addressed proactively, both to mitigate the precursors of burnout and to have the tools and a supportive environment to work through those periods in our life when we experience such an extraordinary amount of stress and emotional exhaustion.

Received August 1, 2007; accepted August 1, 2007; published online: September 25, 2007.

Charles M. Balch, MD, FACS, is Professor of Surgery, Oncology, and Dermatology at the Johns Hopkins Medical Institutions, Baltimore, MD; Edward Copeland, MD, FACS, is currently President of the American College of Surgeons and the Edward R. Woodward Distinguished Professor of Surgery at the University of Florida College of Medicine. Both are past-Presidents of the Society of Surgical Oncology.

Address correspondence and reprint requests to: Charles $\mathrm{M}$ Balch, MD, FACS; E-mail: balchch@jhmi.edu

Published by Springer Science+Business Media, LLC @ 2007 The Society of Surgical Oncology, Inc.

\section{WHAT IS BURNOUT?}

Burnout is characterized by emotional exhaustion, depersonalization, and a decreased sense of personal accomplishment. ${ }^{2-5}$ It is a syndrome present in many individuals under constant pressure. The symptoms and signs of burnout include physical exhaustion, repetitive cynicism, guilt, ineffectiveness, and a sense of depersonalization in relationships with coworkers or patients. ${ }^{4,5}$ Burnout and stress may contribute to alcoholism and drug addiction. Burnout has also been associated with impaired job performance and poor health, including headaches, sleep disturbances, irritability, marital dysfunction, fatigue, hypertension, anxiety, depression, and myocardial infarction. $^{2-6}$ These consequences affect not only personal lives, but family members often suffer as well.

\section{BURNOUT AND JOB SATISFACTION AMONG SURGICAL ONCOLOGISTS}

The good news is that the majority of the SSO participants indicated that they would become a physician again $(78.8 \%)$ and would specifically become a surgical oncologist again $(85.4 \%)$ if they could revisit their career and specialty choice. ${ }^{1}$ These findings should be reinforced to individuals considering a career in surgical oncology as part of efforts to attract the best medical students, residents, and fellows to the field.

On the other hand, according to the SSO survey, $28 \%$ of respondents met the criteria for burnout. ${ }^{1}$ In 
addition, 24\% had high emotional exhaustion, 15\% demonstrated high depersonalization, and $9.6 \%$ had a low sense of personal accomplishment. Approximately $30 \%$ of study participants screened positive for depression. Burnout was more common among respondents age 50 years or younger ( 31 vs $22 \% ; P=$ .029 ) and women (37 vs $26 \% ; P=.031$ ). These statistics indicate that a substantial number of our colleagues are struggling at this point in their career with personal and professional issues at a level that should be of concern to all of us.

There were substantial differences in the characteristics of the geographic practice setting that may directly or indirectly affect the incidence of stress and burnout. Private practice surgical oncologists were more likely to be on call at least three nights per week (29 vs $16.5 \% ; P=.0013$ ) and to perform at least 11 cases per week (48 vs $16 \% ; P \leq .0001$ ). Academic surgical oncologists were more likely to devote at least $25 \%$ of their time to research $(33.3$ vs $6.2 \% ; P<$ .0001 ), to spend more than 3 days per month traveling for work-related purposes (17 vs $8 \% ; P=.004)$, and to work more than 70 hours per week (28 vs $14 \%$; $P \leq .0001)$. Despite these practice differences, there were no differences between private practice and academic physicians in mean emotional exhaustion, depersonalization, or personal accomplishment scores or the frequency of overall burnout. Similarly, there were no differences between private practice and academic physicians in symptoms of depression, potentially problematic alcohol or drug use, or mental or physical quality of life. ${ }^{1}$

\section{WHAT ARE THE CAUSES?}

A number of studies have explored the potential causes of physician burnout. ${ }^{2-6}$ This is clearly a multifactorial and complex issue that affects each of us in differing ways. There appear to be some common themes that impact the largest number of affected individuals. A partial list of potential contributing causes includes:

- Length of training and delayed gratification

- Financial issues (salary, budgets, managed care, etc.)

- More limited control over the delivery of medical services

- Grief and guilt about patient loss or unsatisfactory outcome

- Insufficient protected research time and funding

- Long working hours and enormous workloads
- Feeling isolated/loss of time to connect with colleagues

- Imbalance between career and family

- Inefficient and/or hostile workplace environment

- Gender and age-related issues

In the only other large study of surgeons $(n=582)$, $32 \%$ showed "high" levels of emotional exhaustion, $13 \%$ showed "high" levels of depersonalization, and $4 \%$ showed evidence for low personal accomplishment. ${ }^{7}$ The burnout rate was not related to caseload, practice setting, or percent of patients insured by a health maintenance organization. Important etiologic factors were a sense that work was "overwhelming," a perceived imbalance between career, family, and personal growth, perceptions that career was unrewarding, and lack of autonomy or decision involvement. A strong association was noted between burnout elements and a desire to retire early. ${ }^{7}$

It is beyond the scope of this editorial to explore the intricacies of how these issues might contribute in differing ways to stress and burnout in our practice. The reader is referred to Ref. 1-10 listed below for more details.

\section{WHAT CAN SURGICAL ONCOLOGISTS DO TO PREVENT OR MITIGATE BURNOUT?}

The best prevention for burnout among physicians is to actively nurture and protect their personal and professional well-being on all levels: physical, emotional, psychological, and spiritual. ${ }^{4}$ This needs to occur throughout the professional life cycle of physicians, from medical school through retirement. It is a challenge not only for individual physicians in their own lifestyles, but also for our profession and the organizations in which physicians work. ${ }^{4}$ Indeed, the leadership of institutions, departments of surgery, and professional societies, such as the SSO and the American College of Surgeons, should encourage and define workplace activities that allow for a balanced professional lifestyle. The old aphorism of "we did it that way" is no longer tenable if we wish to continue attracting the brightest and best talent from medical school and surgical residencies ... and for them to be fulfilled as we have been.

Personal growth and renewal involve not only the time outside of work (evenings, weekends, or vacations). Strategies that may help increase wellness for individual surgical oncologists include participating in research, continuing educational activities outside of work, and paying particular attention to important 
personal relationships, spiritual practices, recognizing the importance of one's work, cultivating personal interests outside of work, and creating a balance between personal and professional life. ${ }^{1,3,5,6}$ Each of us have our own combination of activities that can be self-renewing and energizing that no doubt will change as we go through phases of our career and our seasons of life. What is required is a new way of thinking about one's personal energy - that work is not merely a domain of energy expenditure but also of energy renewal. Physicians can learn to receive support, healing, and meaning while giving of themselves in each professional activity of the day. ${ }^{4}$

A benefit of publishing surveys such as this is that those going through a personal crisis and burnout should know that they are not alone and that many of their colleagues face similar issues. It would be a mistake for one of our readers facing this to think: "I must not be tough enough" . . . or "no one could possibly experience what I am going through." There is some evidence that those who are most dedicated to their profession and their patient care may very well be most susceptible. Silence on career distress as a policy simply does not work among professionals whose careers, well-being, and level of patient care may be in jeopardy. Being silent about career distress to family or colleagues simply delays addressing the heart of the matter and may exacerbate the problem.

\section{THE IMPORTANCE OF HAVING GOOD MENTORS}

We should encourage more research in this area at all levels of our profession and design systematic interventions to help future surgeons both recognize and prevent burnout so that they can maintain resilience throughout their career. In this regard, the critical importance of positive mentorship cannot be underestimated. ${ }^{9,10}$ This applies not only for mid and later level clinicians and faculty, but early on for our medical students and surgical trainees. ${ }^{1,6,9}$ Unfortunately, some habits developed during the training process may promote unhealthy approaches for dealing with the stress of practice and believing the myth that "things will get better after the completion of training." 6

Healthcare organizations have an economic stake in the well-being of physicians. Workers who are satisfied tend to be more productive. There is evidence that the well-being of physicians is related to patient quality of care and satisfaction, a key outcome variable that is tracked by most organizations.
Further, attention to well-being promotes patient safety and reduces the probability of poor judgment, medical errors, and, consequently, the threat of malpractice litigation.,

\section{CONCLUSION}

We hope all our readers will take notice of this important article and will work proactively to enhance their own coping skills and seek counsel as appropriate over stressful issues.

We all chose to pursue the arduous task of becoming a surgical oncologist to change the lives of individuals with a potentially lethal disease, to have patients put their hopes and futures in our hands, to experience the joy of accomplishing a cure, and to accept the responsibility of supporting them when we do not. Some of us have chosen to advance our field through research and teaching. A primary source of gratification should come from the expert care we provide to our patients and to their family as we apply our knowledge and skills to the betterment of present and future cancer patients.

Most importantly, each surgical oncologist must continuously map their own career pathway that integrates their personal and professional goals with the outcome of maintaining value, balance, and personal satisfaction throughout their professional career.

There is no single formula for achieving a satisfying professional career that can be applied to such a diverse set of practice environments as surgical oncology. No doubt every one of us has (or will have) to deal with stressful issues in our personal and professional life on a regular basis. Being proactive is so much better than reacting to a situation that can spiral into a crisis that damages one's professional life or personal wellness and may take months or years to repair. We physicians must be guided from the earliest years of training to cultivate methods of personal renewal, emotional self-awareness, connection with social support systems, and a sense of mastery and meaning in their work. Maintaining these values is the work of a lifetime.

Dr. Shanafelt, a medical oncology colleague, has published several outstanding articles on this subject, and we commend these articles to you. ${ }^{2,3,6}$ We have reproduced a table from one of his articles listing "Steps to Promote Personal Well-Being" that can serve as a template for personal inventory (Table 1). ${ }^{2}$

We congratulate Dr. Kuerer and the SSO leadership for initiating this survey and for their significant contribution to the literature about this vitally important 
TABLE 1. Steps to promote personal well-being

1. Identify personal and professional values and priorities.

a. Reflect on personal values and priorities.

b. Strive to achieve balance between personal and professional lives.

i. Make a list of personal values and priorities; rank in order of importance.

ii. Make a list of professional values and priorities; rank in order of priorities.

iii. Integrate these two lists.

iv. Identify areas of conflict where personal and professional goals may be incompatible.

c. Based on priorities, determine how conflicts should be managed.

2. Enhance areas of work that are most personally meaningful.

a. Identify areas of work are most meaningful to you (patient care, patient education, medical education, participation in clinical trials, research, administration).

b. Find how you can reshape your practice to increase your focus in this area(s).

c. Decide if improving your skills in a specific area would decrease your stress at work, or if seeking additional training in this or other areas be helpful for you.

d. Identify opportunities to reflect with colleagues about stressful and rewarding aspects of practice.

e. Periodically reassess what you enjoy most about your work.

3. Identify and nurture personal wellness strategies of importance to you.

a. Protect and nurture your relationships.

b. Nurture religion/spirituality practices.

c. Develop hobbies and use vacations to encourage nonmedical interests.

d. Ensure adequate sleep, exercise, and nutrition.

e. Define and protect time for personal reflection at least monthly.

f. Obtain a personal primary care provider and seek regular medical care.

subject. We would encourage the Society of Surgical Oncology, the American College of Surgeons, and other organizations to continue studying this issue, and we plan to follow up with additional articles on this topic in future issues of the Annals as well.

\section{REFERENCES}

1. Kuerer, H, Eberlein, T, Pollock, R, Huschka, M, Baile, W, Morrow, M. et al. Career Satisfaction, Practice Patterns and Burnout among Surgical Oncologists: Report on the Quality of Life of Members of the Society of Surgical Oncology, Ann Surg Oncol 14; doi:10.1245/s10434-007-9579-1 2007.

2. Shanafelt TD. Finding meaning, balance, and personal satisfaction in the practice of oncology. J Support Oncol 2005; $3: 157-162 ; 164$.
3. Shanafelt TD, Sloan JA, Habermann TM. The well-being of physicians. Am J Med 2003; 14:513-9.

4. Spickard A, Gabbard G, Christensen JF. Mid-career burnout in generalist and specialist physicians: definitions, risk factors and prevention. JAMA 2002; 288:1447-50.

5. Meier DE, Back AL, Morrison RS. The inner life of physicians and care of the seriously ill. JAMA 2001; 286:3007-14.

6. Shanafelt T, Chung H, White H, Lyckholm. Shaping your career to maximize personal satisfaction in the practice of oncology. J Clin Oncol 2006;24:4020-6.

7. Campbell DA Jr, Sonnad SS, Eckhauser FE, et al. Burnout among American surgeons. Surgery. 2001; 130:696-702.

8. Höckerstedt K. Surgeons' self-esteem. A change from too high to too low?. Ann Surg 2006; 244:841-4.

9. Copeland EM. The role of the young academic surgeon in American surgery. J Surg Res 1980; 28:191-7.

10. Copeland EM. The role of a mentor in creating a surgical way of life. Bull Am Coll Surg 2006; 91:8-13. 